N $63 \quad 16292$

NASA TN D-1721

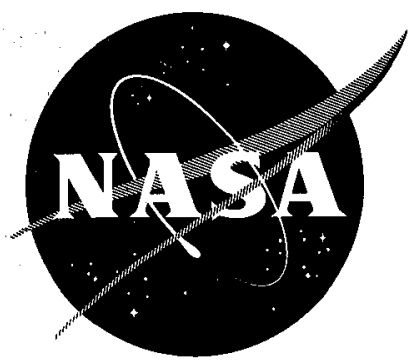

TECHNICAL NOTE

D-|72|

\title{
THE EFFECT OF REFRACTION ON THE SETTING SUN AS SEEN FROM SPACE IN THEORY AND OBSERVATION
}

\author{
Winifred Sawtell Cameron \\ Goddard Space Flight Center \\ Lt. Col. John H. Glenn \\ U. S. Marine Corps \\ Lt. Cdr. M. Scott Carpenter \\ U. S. Navy \\ John A. O'Keefe \\ Goddard Space Flight Center
}

NATIONAL AERONAUTICS AND SPACE ADMINISTRATION WASHINGTON

May 1963 


\title{
THE EFFECT OF REFRACTION ON THE SETTING SUN AS SEEN FROM SPACE IN THEORY AND OBSERVATION
}

\author{
by \\ Winifred Sawtell Cameron \\ Goddard Space Flight Center \\ Lt. Col. John H. Glenn \\ U. S. Marine Corps \\ Lt. Cdr. M. Scott Carpenter \\ U. S. Navy \\ John A. O'Keefe \\ Goddard Space Flight Center
}

\begin{abstract}
SUMMARY
The theory of refraction predicts that the setting sun or moon as seen from space should be highly flattened. The Mercury Project Manned Space Flights MA-6 and MA-7 have provided photographs of the phenomenon. To compare theory with observation, B. Garfinkel's Method I of computing refraction for large zenith distances was used to construct theoretical solar profiles for four true zenith distances of the center of the setting sun for comparison with the photographs taken by Glenn and Carpenter.
\end{abstract}


Page Intentionally Left Blank 
CONTENTS

Summary $\ldots \ldots \ldots \ldots \ldots \ldots \ldots \ldots \ldots \ldots$

INTRODUCTION. ....................... 1

A THEORETICAL SOLAR PROFILE. ............. 1

COMPARISON OF PHOTOGRAPHIC AND COMPUTED DATA. . . 7 ACKNOWLEDGMENTS ................... 7 


\title{
THE EFFECT OF REFRACTION ON THE SETTING SUN AS SEEN FROM SPACE IN THEORY AND OBSERVATION
}

\author{
by \\ Winifred Sawtell Cameron \\ Goddard Space Flight Center \\ Lt. Col. John H. Glenn \\ U. S. Marine Corps \\ Lt. Cdr. M. Scott Carpenter \\ U. S. Navy \\ John A. O'Keefe \\ Goddard Space Flight Center
}

\section{INTRODUCTION}

The problem of the refraction of light by the earth's atmosphere as seen from a space capsule differs essentially from the problem as seen from the surface of the earth. At the earth's surface it is possible to calculate the astronomical refraction within 1 second of arc by Comstock's formula down to elevation angles of $15^{\circ}$ above the horizon. Comstock's formula which depends only on the elevation angle and the index of refraction at the observer, would be the same if the earth were flat and surrounded by a 100-ft atmosphere. Near the horizon, it is true, terms involving the scale height and the curvature of the earth must be introduced. The problem of the lateral displacement of the ray by refraction is hardly considered, except in certain eclipse calculations.

In the case of the capsule, on the other hand, owing to the great distance (of the order of $1000 \mathrm{~km}$ ) from the observer to the relevant region of the atmosphere, the variation of the refractive index with path is an essential part of the computation. We cannot approach the problem without a good knowledge of the scale height and of the curvature of the earth. The lateral displacement of the ray is relatively enormous.

The observation of the rising and setting of the sun in Mercury Project manned orbital flights has emphasized the need for a more complete theory. The solar image should appear strongly flattenedalmost sausage-shaped. Astronauts Glenn and Carpenter obtained photographs of the setting sun that illustrate this rather striking effect.

\section{A THEORETICAL SOLAR PROFILE}

The general procedure for computing refraction at extreme altitudes is presented in order to construct a theoretical solar profile for comparison with photographic data. The procedure is applied to 
Carpenter's orbital conditions on May 24, 1962. The quantities to be determined are the apparent zenith distance $Z_{\text {ap }}$ and the true zenith distance $Z_{t r u e}$, as seen from the capsule. To find these a ray through the atmosphere to the capsule is idealized. The phenomenon occurs effectively only for rays whose perigees are less than $20 \mathrm{~km}$ above the earth's surface. Thus we consider rays at $2 \mathrm{~km}$ intervals up to an altitude $\mathrm{h}$ of $20 \mathrm{~km}$.

In Figure 1, the ray from the sun is traced backward from the capsule C. In the first section, from the spacecraft to the atmosphere, $\mathrm{X}$ is straight. If the ray continued in this direction toward the sun, there would be a point $B$ of nearest approach to the center of the earth 0 . This distance is denoted by $p$, and the angle at the center of the earth from the capsule to $B$ by $\Theta$. If $B$ and $p$ are known, the apparent height of any point on the sun (as seen from the spacecraft) could be calculated. To make the calculation, the curving optical ray is followed forward until it is refracted so as to be parallel to the surface of the earth. This point is called the perigee of the ray, and is denoted by G. The line OG makes an angle $\Theta+r$ with $\propto C$, where $r$ is the refraction angle for the sun when it is seen $90^{\circ}$ from the zenith by an imaginary observer at $\mathrm{G}$.

If the straightportion of the ray is prolonged, it will intersect $0 . G$ at some point $D$. Then the height of $\mathrm{D}$ above $\mathrm{G}$ is called the refractive height $\mathrm{s}$. For any given height, say $\mathrm{G}$, the refraction angle $r$ at the horizon and the refractive height $s$ which depends on the true height and $r$ can be calculated. Then

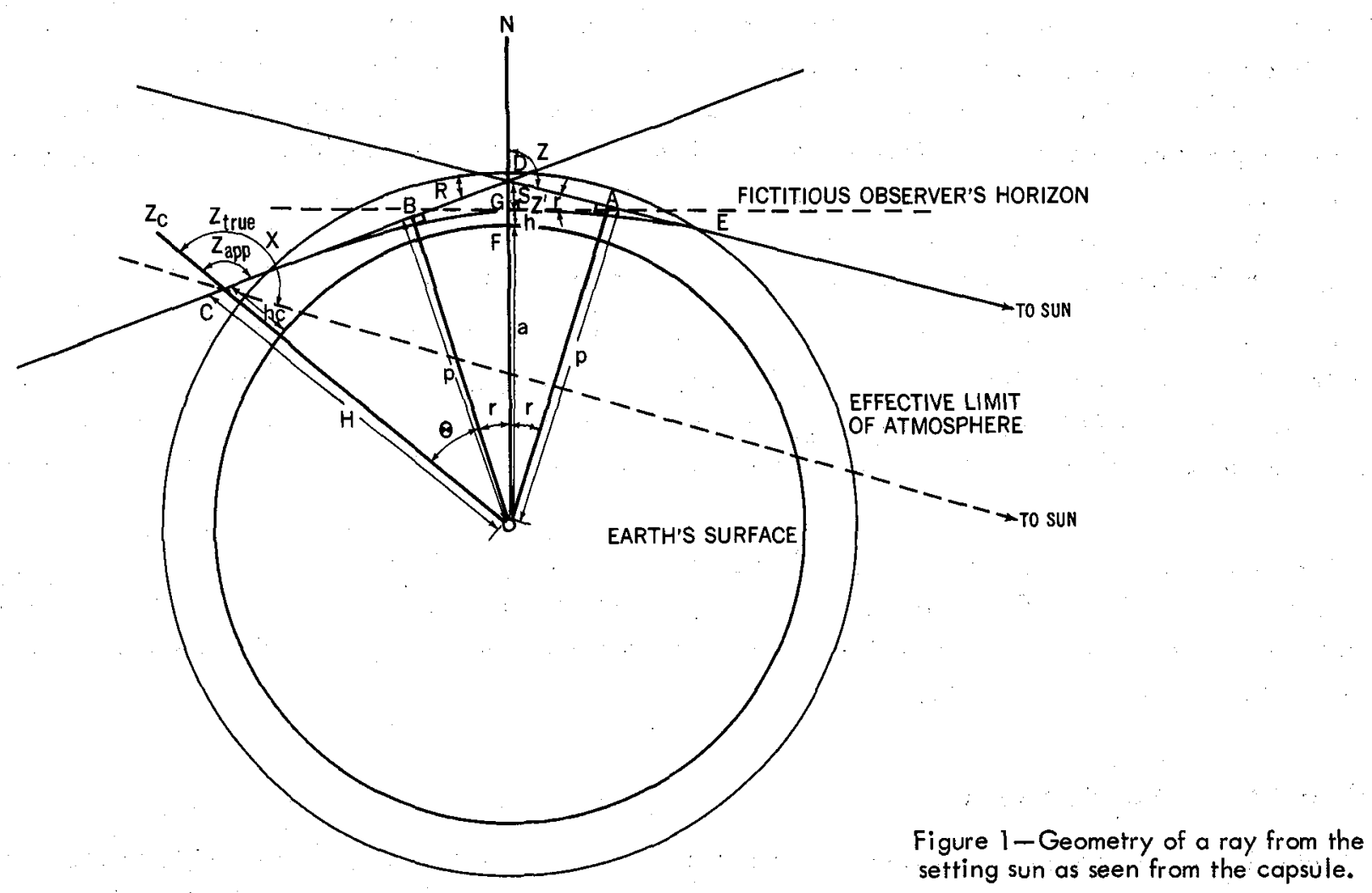


the right triangle OBD can be solved for the distance p from the center of the earth to the straight-line prolongation of the space portion of the ray $\mathrm{C}$. The length $\mathrm{p}$ is denoted, by analogy with the similar dynamical problem, as the impact parameter.

Thus given $\mathrm{p}$ and the capsule height, the apparent angles at the spacecraft can be calculated as a function of $\Theta$. The refraction angle $R=2 r$ is added to $\Theta$ to form the true zenith distance.

The computation of the refraction $r=z-z^{\prime}$, where $z$ is the true zenith distance and $z^{\prime}$ the apparent zenith distance, for the imaginary observer stationed at perigee, was based on the rather detailed theory of B. Garfinkel (Method I).* The pertinent formulas are:

$$
\begin{aligned}
& r=\mathrm{T}^{1 / 2} \sum_{\mathrm{i}=0}^{5} \mathrm{~B}_{\mathrm{i}} \mathrm{W}^{\mathrm{i}+1}, \\
& \cot \theta=\gamma \mathrm{T}^{-1 / 2} \cot z, \\
& W=P \mathrm{~T}^{-2},
\end{aligned}
$$

where $z$ is $90^{\circ}$, $\mathrm{T}$ the absolute temperature at h divided by $273 .{ }^{\circ} 0, \mathrm{P}$ the pressure at $\mathrm{h}$ divided by the ground pressure of $1.013 \times 10^{6} \mathrm{dynes} / \mathrm{cm}^{2}, \mathrm{~B}$ a coefficient involving the index of refraction $\mu$ and the polytropic index $n$ (for $z=90^{\circ}: B_{0}=2012 \prime \prime 2, B_{1}=168^{\prime \prime}, B_{2}=21^{\prime \prime}: 8, B_{3}=3.2, B_{4}=0.5$ ), and $\gamma$ a constant dependent upon $\mathrm{n}$.

The temperature, pressure and density $(\delta)$ of the atmosphere at an altitude $\mathrm{h}$ were taken from the Rocket Panel data. ${ }^{\dagger}$ More recent data are available from CIRA, $\S$ but the results are not significantly different for this computation.

For greater accuracy than required here, corrections to the approximations of Garfinkel's method may be made with the formula:

$$
\mathbf{E}=\epsilon_{1}+\epsilon_{2}+\epsilon_{3}+\epsilon_{4}=\mathbf{F}_{1} \mathbf{p T}^{-1 / 2}+\frac{\mathbf{F}_{2} \mathrm{hR}}{10^{4}}+\epsilon_{3}+\mathrm{T}^{1 / 2} \csc \theta \sum_{\mathrm{i}=\sigma}^{\infty} \mathrm{J}_{\mathrm{i}}\left(w \tan ^{2} \frac{\theta}{2}\right)^{\mathrm{i}+1} \delta \mathrm{n}
$$

where $F_{1}, F_{2}, J_{0}, J_{1}, J_{2}$ are tabulated as functions of $\theta$, and $\epsilon_{3}$ is tabulated as a function of $:\left|90^{\circ}-z\right|$ and $h$. Note that a factor of $10^{4}$ was omitted in Garfinkel's paper and $\epsilon_{2}$ should be computed according to the above equation.

\footnotetext{
"Garfinkel, B., "An Investigation in the Theory of the Astronomical Refraction," Astronom. J. 50(8):169-179, February 1944.

†The Rocket Panel, "Pressures, Densities, and Temperatures in the Upper Atmosphere," Phys. Rev. 88(5):1027-1032, December 1, 1952. \$International Council of Scientific Unions, Committee on Space Research, Preparatory Group for an International Reference Atmosphere, "CIRA 1961: COSPAR International Reference Atmosphere, 1961; Report Accepted at the COSPAR Meeting in Florence, April, 1961, comp. by H. Kallmann-Bijl, R. L. F. Boyd, et al., Amsterdam: North-Holland Publ. Co., 1961.
} 
The parameter s, which we called the ref ractive height, is a ref raction correction commonly applied in calculations of times of contact in eclipses. The derivation of $\mathrm{s}$ is to be found in Chauvenet.* His Equation 564 gives its relation to the index of refraction as $1+\mathrm{s} / \mathrm{a}=\mu\left(\sin z^{\prime}\right) / \sin z$, where $a$ is the mean radius of the earth $(6,371,020 \mathrm{~m}), \mu$ the index of refraction at $h, z^{\prime}$ the apparent zenith distance $\left(90^{\circ}\right)$ for a fictitious observer at $G$, and $z$ the true zenith distance $\left(z^{\prime}+r\right)$ at the same point.

When $\mu, \mathrm{r}$, and $\mathrm{s}$ have been obtained, $\mathrm{p}$ is obtained from the equation $\mathrm{p}=(\mathrm{a}+\mathrm{h}+\mathrm{s}) \cos \mathrm{r}$. $\Theta$ is then determined from the relation $\cos \Theta=p / H$, where $H=a+h_{c} ; h_{c}=257,000 m$ as determined by the orbit computed from the final definitive elements of Carpenter's orbit. Finally, $z_{\text {app }}$ and $Z_{t r u e}$ are related to $\Theta$ and $R$ such that $Z_{a p p}=90^{\circ}+\Theta$ and $Z_{t r u e}=90^{\circ}+(\Theta+R)$. The computed results are summarized in Table 1.

The flattening of the image of the setting sun may be illustrated by plotting $Z_{\mathrm{app}}$ against $Z_{\mathrm{true}}$. An image representing the sun (to scale) may be placed at any $z_{t_{r u e}}$, and points around the limb, extended to the curve, may be located on the $z_{\text {app }}$ axis, thereby giving the apparent zenith distance of each point. Since the horizontal

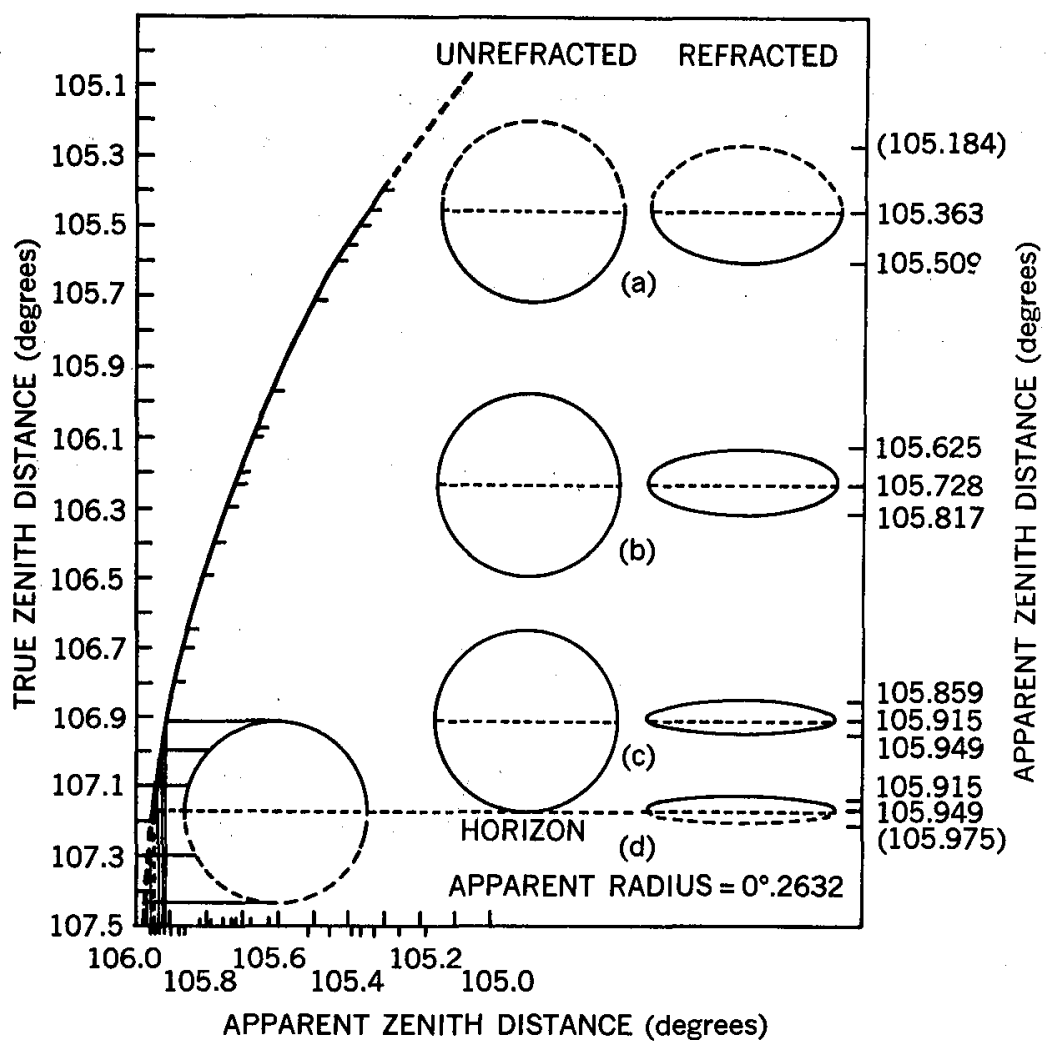

Figure 2-Stages of the setting sun for four zenith distances. axis is not affected by refraction, parallels of altitude (almucantars) may be laid off on the unrefracted image of the sun, and similarly laid off on the apparent image of the sun. The latter may be rectified for easy comparison. The theoretical profiles of four phases of a setting sun are illustrated in Figure 2. Here $z_{t \text { rue }}$ versus $z_{a p p}$ is plotted with images of the sun given for four true zenith distances of the sun's center: (Figure 2a) $z_{\text {true }}=105^{\circ} .455$; (Figure $2 \mathrm{~b}$ ) $z_{\text {true }}=106^{\circ} .231$; (Figure 2c) $z_{\text {true }}=106^{\circ} .915$ (sun's lower limb on the horizon) and (Figure 2d) $Z_{\text {true }}=107^{\circ} .175$ (sun's center on horizon). The ratio of the vertical to horizontal diameters are approximately $0.63,0.36,0.17$, and 0.11 respectively. Considering the capsule angular velocity $\left(4^{\circ} / \mathrm{min}\right)$,

\footnotetext{
*Chauvenet, W., "A Manual of Spherical and Practical Astronomy," 5th Ed., Vol. 1, New York: Dover Publ., 1960.
} 
Table 1

Data Obtained in the Computation of the Apparent and True Zenith Distances using the Final Definitive Elements of the MA-7 Orbit.

\begin{tabular}{|c|c|c|c|c|c|c|c|c|c|c|}
\hline $\begin{array}{c}\text { Altitude } \\
\text { h } \\
\text { (meters) }\end{array}$ & $\frac{\text { Temperature }}{273.0^{\circ} \mathrm{K}}$ & $\frac{\text { Pressure }}{1.013 \times 10^{6} \text { dynes } / \mathrm{cm}^{2}}$ & $\begin{array}{c}\text { Ratio } \\
\text { of Densities* } \\
\delta\end{array}$ & $\begin{array}{c}\text { Refraction } \\
\mathrm{r} \\
\text { (minutes } \\
\text { of arc) }\end{array}$ & $\begin{array}{c}\text { Index of } \\
\text { Refraction } \\
\mu\end{array}$ & $\begin{array}{c}\text { Refractive } \\
\text {.Height } \\
\text { s } \\
\text { (meters) }\end{array}$ & $\begin{array}{c}\text { Impact } \\
\text { Parameter } \\
\mathrm{p} \\
\text { (meters) }\end{array}$ & $\begin{array}{c}\Theta \\
\text { (degrees) }\end{array}$ & $\begin{array}{l}\text { Apparent } \\
\text { Zenith } \\
\text { Distance } \\
Z_{\text {app }} \\
\text { (degrees) }\end{array}$ & $\begin{array}{c}\text { True } \\
\text { Zenith } \\
\text { Distance } \\
Z_{\text {true }} \\
\text { (degrees) }\end{array}$ \\
\hline 0000 & 1.0000 & 1.0000 & 1.0000 & 36.765 & 1.0002944 & 2240.1 & 6372896 & 15.949 & 105.949 & 107.175 \\
\hline 2000 & 1.0330 & 0.7932 & 0.8532 & 27.081 & 1.0002512 & 1797.9 & 6374620 & 15.894 & 105.894 & 106.797 \\
\hline 4000 & 0.9985 & 0.6214 & 0.6903 & 22.073 & 1.0002032 & 1425.8 & 6376314 & 15.841 & 105.841 & 106.577 \\
\hline 6000 & 0.9524 & 0.4812 & 0.5611 & 18.188 & 1.0001652 & 1141.7 & 6378072 & 15.785 & 105.785 & 106.391 \\
\hline 8000 & 0.8974 & 0.3676 & 0.4551 & 15.092 & 1.0001340 & 915.5 & 6379873 & 15.728 & 105.728 & 106.231 \\
\hline 10000 & 0.8454 & 0.2757 & 0.3623 & 12.299 & 1.0001067 & 720.6 & 6381699 & 15.669 & 105.669 & 106.079 \\
\hline 12000 & 0.8040 & 0.2038 & 0.2819 & 9.742 & 1.0000830 & 554.3 & 6383548 & 15.610 & 105.610 & 105.935 \\
\hline 14000 & 0.7751 & 0.1488 & 0.2128 & 7.468 & 1.0000626 & 413.5 & 6385419 & 15.550 & 105.550 & 105.799 \\
\hline 16000 & 0.7619 & 0.1075 & 0.1567 & 5.508 & 1.0000461 & 302.0 & 6387313 & 15.489 & 105.489 & 105.673 \\
\hline 18000 & 0.7656 & 0.0775 & 0.1124 & 3.922 & 1.0000331 & 214.7 & 6389231 & 15.426 & 105.426 & 105.557 \\
\hline 20000 & 0.7795 & 0.0562 & 0.0802 & 2.757 & 1.0000236 & 152.3 & 6391170 & 15.363 & 105.363 & 105.455 \\
\hline
\end{tabular}

* $\delta$ is the density at h divided by the density at the earth's surface $\left(1.72 \times 10^{-3} \mathrm{gm} / \mathrm{cm}^{3}\right)$ and is tabulated for the computation of $\mu$. 


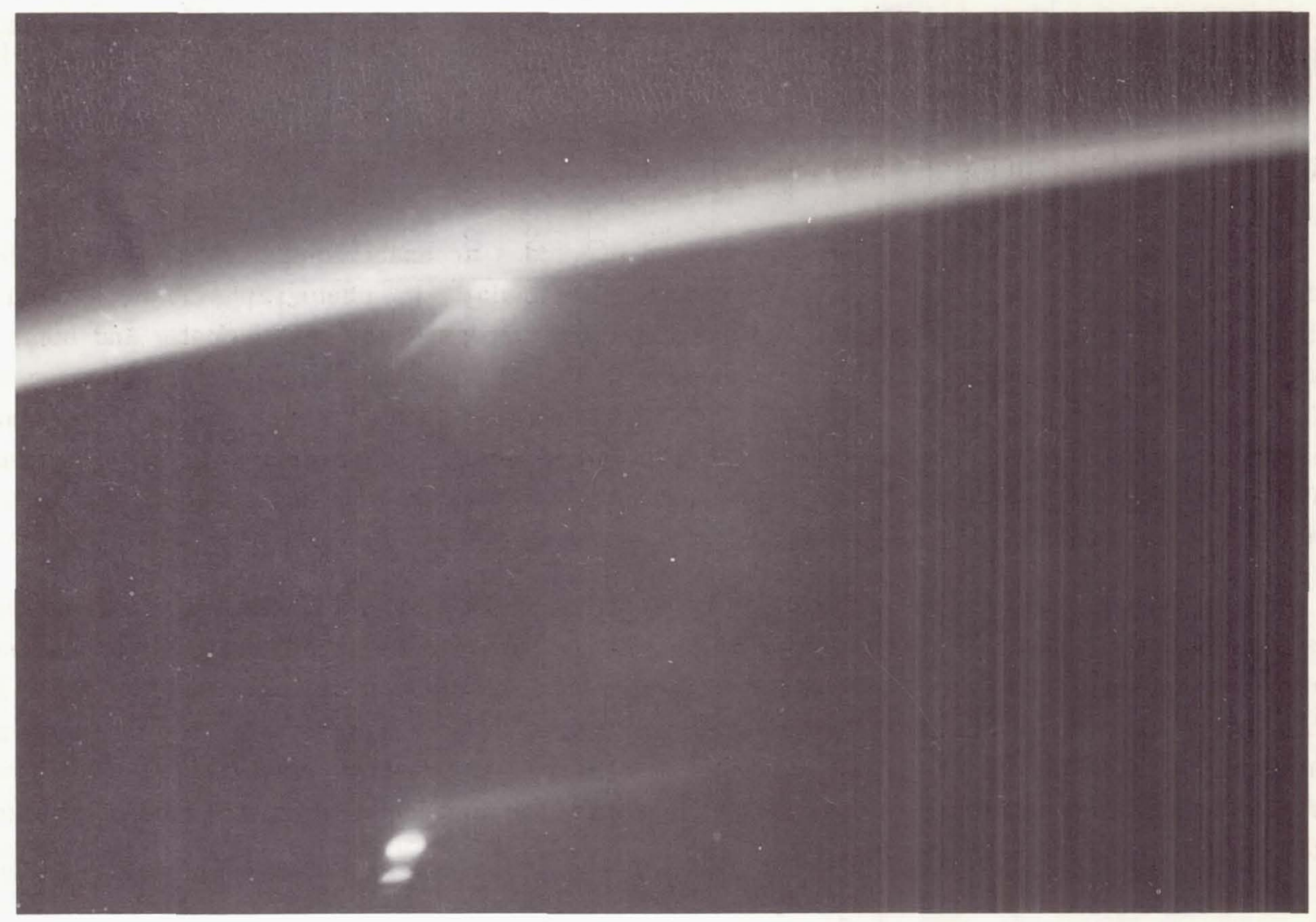

Figure 3-Photograph of setting sun taken by Glenn on the MA-6 orbital flight.

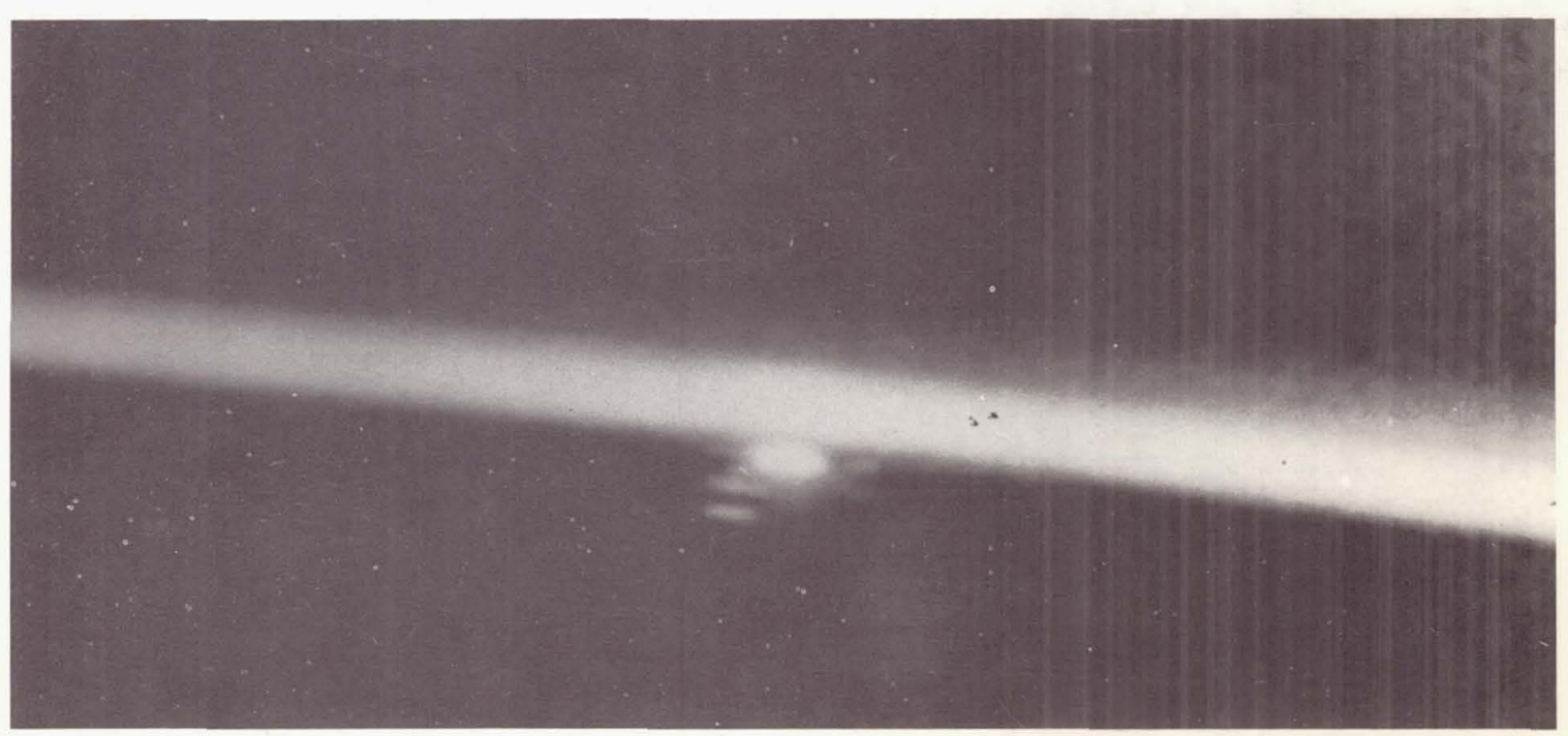

Figure 4-Photograph of setting sun taken by Carpenter on the MA-7 orbital flight. 
we see that the entire effect treated herein would occur for the astronaut during a relatively short time interval (about 20 seconds).

\section{COMPARISON OF PHOTOGRAPHIC AND COMPUTED DATA}

Uncertainty of time in the photographic record precludes an exact comparison of theory and observations. However, Figure 2c perhaps most nearly simulates the photographs (Figures 3 and 4), which show the effects of the capsule's motion-somewhat increased vertical diameter and some lateral motion-of the image but still demonstrate the effect. Figure 3 was photographed on the MA-6 orbital flight of February 20, 1962. The sun was not seen then as a narrow, flat object, but instead was seen to spread out about ten degrees on either side and to merge with the twilight band. In the original photograph the true setting sun and horizon appear with reflections both above and below. The phenomenon is perhaps more clearly seen in the lower reflection, as shown in Figure 3.

Figure 4 was photographed on the MA-7 orbital flight on May 24, 1962. At that time the sun was observed to be definitely flattened during sunrise and sunset and very similar to its appearance in the photographs. The flattening effect of refraction on a setting celestial object as seen above the atmosphere-a condition simulated by the capsule in orbit-has been demonstrated by direct observation on the MA-6 and MA-7 flights. However, it is hoped that on future missions photographs with precise observation times; and perhaps measurements of the apparent vertical and horizontal diameters with a sextant will be feasible.

\section{ACKNOWLEDGMENTS}

The authors take pleasure in acknowledging the assistance of Mr. James Donegan, Goddard Space Flight Center, for making available the final orbit elements and to Mr. Frederick B. Shaffer, Goddard Space Flight Center, for programming the orbit on the 7090 computer. 